\title{
Потенциометрическая мультисенсорная система на основе мембран МФ-4СК, содержащих оксид кремния с функционализированной поверхностью, для определения ионов сульфаниламида и калия
}

\author{
Ельникова А.С., Колганова Т.С., Паршина А.В., Бобрешова О.В. \\ Воронежский государственный университет, Воронеж
}

Поступила в редакцию 04.11.2020 г.

DOI: $10.17308 /$ sorpchrom.2020.20/3054

\begin{abstract}
Сульфаниламидные препараты широко используются в медицине и ветеринарии. Для контроля над содержанием остаточных количеств сульфаниламидов в пищевых продуктах, питьевой воде, объектах окружающей среды и анализа фармацевтических препаратов известны методики ВЭЖХ, капиллярного электрофореза, спектрофотометрии, титриметрии. В то же время, число сенсоров для их определения ограничено. Целью работы была разработка потенциометрической мультисенсорной системы с ПД-сенсорами (ПД - потенциал Доннана) для определения анионов и цвиттер-ионов сульфаниламида совместно с катионами калия в водных растворах в широком диапазоне рН. Материалами ПД-сенсоров были перфтормембраны МФ-4СК, которые содержали наночастицы оксида кремния с поверхностью, модифицированной группами 3-аминопропила и 3-(2-имидазолин-1-ил)пропила. Чувствительность ПД-сенсоров на основе исследуемых мембран к цвиттер-ионам и анионам сульфаниламида является значимой в диапазоне концентраций от $1.0 \cdot 10^{-4}$ до $1.0 \cdot 10^{-2} \mathrm{M}$. Это обусловлено протонированием анионов сульфаниламида в мембране вследствие разности рН внешнего и внутреннего растворов. При этом наличие в структуре аналита положительно заряженной ароматической аминогруппы и отрицательно заряженной сульфонамидной группы обеспечивает взаимодействие с сульфогруппами мембраны и аминогруппами на поверхности допанта, соответственно. Для организации мультисенсорной системы была выбрана мембрана МФ-4СК + 3 мас.\% $\mathrm{SiO}_{2}(10$ мол.\% R1) с наиболее высокой чувствительностью к ионам сульфаниламида, а также мембрана МФ-4СК + 3 мас.\% $\mathrm{SiO}_{2}$, которые в паре обеспечивают наименьшую корреляцию между откликами сенсоров в системе. Относительная погрешность и относительное стандартное отклонение определения ионов сульфаниламида составили 3-9 и 8-16\%, ионов калия - 0.4-14 и 3-14\%, соответственно. Преимуществами разработанной мультисенсорной системы для определения сульфаниламида в водных растворах по сравнению с рекомендованной Государственной Фармакопеей методикой нитритометрии являются экспрессность, отсутствие необходимости коррекции $\mathrm{pH}$ и использования других реактивов, а также возможность определения сульфаниламида совместно с ионами щелочных металлов, являющимися компонентами фармвцевтических и технологических сред.

Ключевые слова: ПД-сенсоры, мультисенсорные системы, перфторированные сульфокатионообменные мембраны, оксид кремния, функционализация поверхности допанта, гибридные материалы, сульфаниламид.
\end{abstract}

\section{Введение}

Сульфаниламид является представителем синтетических противомикробных средств широкого спектра действия. Широкое использование сульфаниламидов в медицине и ветеринарии приводит к загрязнению продуктов питания животного происхождения [1, 2], а также объектов окружающей среды [3]. ГОСТ устанавливает метод ВЭЖХ с масс-спектрометрическим детектированием для определения оста- 
точного содержания сульфаниламидов в продовольственном сырье и пищевых продуктах [4]. В фармакопейном анализе для определения сульфаниламидов используют метод нитритометрии [5].

В современных исследованиях для определения сульфаниламидов в пищевых продуктах, питьевой воде, объектах окружающей среды и фармацевтических препаратах используют ВЭЖХ $[6,7]$, капиллярный электрофорез $[8,9]$, спектральные методы $[1,10,11]$, а также электрохимические сенсоры $[2,12-16]$ и биосенсоры [17]. Разработке новых методик определения сульфаниламидов способствует, в том числе, использование новых композитных материалов для их определения и подготовки проб к анализу. Авторами [6] синтезирован сорбент на основе полиуретана и оксида графена для подготовки проб молока для последующего определения сульфаниламида, сульфатиазола, сульфаметиозола и сульфадиазина методом ВЭЖХ с УФдетектированием. В работе [8] показана эффективность использования наночастиц графен $/ \mathrm{Fe}_{3} \mathrm{O}_{4}$ в качестве сорбента для твердофазной экстракции сульфаниламидов из молока при их определении в нем методом капиллярного электрофореза. Авторами [11] получен композитный материал на основе молекулярно импринтированного полимера и наночастиц $\mathrm{Fe}_{3} \mathrm{O}_{4}$ для обнаружения сульфаметоксазола в морской воде методом импедансной спектроскопии. Для определения сульфаниламида в свинине разработаны вольтамперометрические сенсоры на основе стеклоуглеродных электродов, модифицированных композитным материалом графен $/ \mathrm{Fe}_{3} \mathrm{O}_{4}$ [12] и карбоксилированными МУНТ [2]. Авторами [13] разработан вольтамперометрический сенсор на основе электрода из пиролитического графита и композитной пленки ОУНТ/поли 1,5-диаминонафталин для определения сульфацетамида в глазных каплях. Описанные потенциометрические сенсоры для определения сульфаниламидов включают анионообменники в качестве ионофора. Разработаны потенциометрические сенсоры на основе графита и пластифицированных ПВХ-мембран с солями четвертичного аммония и железо(II)-фталоцианином для определения сульфадиазина в фармацевтических препаратах и моче [14]. Известен потенциометрический сенсор на основе углеродной пасты и комплекса сульфахиноксалина натрия с 2,3,5трифенилтетразолий хлоридом для определения сульфацетамида в фармацевтическом препарате, молоке, сыворотке крови и моче [15]. Потенциометрические сенсоры с внутренним раствором сравнения на основе пластифицированных ПВХмембран и ассоциатов аналитов с тетрадециламмонием использованы для определения сульфадиметоксина и сульфадимезина в таблетках [16].

Данная работа направлена на разработку потенциометрической мультисенсорной системы для совместного определения цвиттер-ионов, анионов сульфаниламида и катионов калия в водных растворах в широком диапазоне $\mathrm{pH}$. Основой мультисенсорной системы являются сенсоры с внутренним раствором сравнения, аналитическим сигналом которых является потенциал Доннана (ПД) $[18,19]$. Возможности выбора анионообменных материалов для сенсоров ограничены. Поэтому в данной работе для организации сенсоров, перекрестно чувствительных к ионам противоположного знака, а также биполярным ионам, предложено использовать перфтормембраны МФ-4СК, которые содержат наночастицы оксида кремния с поверхностью, модифицированной протоноакцепторными группами. Известно, что необменная сорбция может вносить существенный вклад в поглощение электролита мембраной. Предполагали, что сорбции ионов органического амфолита будет способствовать присутствие в мембране реакционных центров с различными кислотноосновными свойствами - сульфогрупп мембраны и аминогрупп на поверхности допанта.

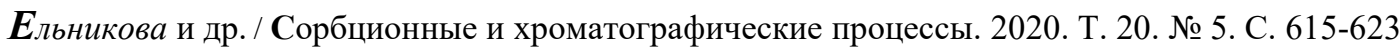


Целью работы была разработка мультисенсорной системы на основе мембран МФ-4СК, содержащих наночастицы оксида кремния, поверхностно модифицированные группами 3-аминопропила и 3-(2-имидазолин-1-ил)пропила, для совместного определения цвиттер-ионов, анионов сульфаниламида и катионов калия в водных растворах.

\section{Экспериментальная часть}

Объекты исследования. Исследовали водные растворы сульфаниламида (4аминобензолсульфонамида, SA), содержащие калия гидроксид. Для их приготовления использовали сульфаниламид (ООО «Сигма-Алдрич Рус», х.ч.), калия гидроксид (ООО «Экохим», х.ч.) и бидистиллированную воду (сопротивление $18.2 \mathrm{MOм,} \mathrm{pH}$ $5.41 \pm 0.05)$. Концентрация компонентов в растворах варьировалась от $1.0 \cdot 10^{-4}$ до $1.0 \cdot 10^{-2} \mathrm{M}$ в различном соотношении. Значения $\mathrm{pH}$ растворов изменялись от $9.33 \pm 0.03$ до $10.98 \pm 0.06$. Учитывая значения констант диссоциации функциональных групп сульфаниламида $\left(\mathrm{pK}\left(-\mathrm{SO}_{2} \mathrm{NH}_{2}\right)=2.4, \mathrm{pK}\left(-\mathrm{NH}_{3}{ }^{+}\right)=10.4\right.$ [20]), в исследуемом диапазоне $\mathrm{pH}$ аналит находится в форме цвиттер-ионов $\left(\mathrm{SA}^{ \pm}\right)$и анионов (SA') (рис. 1).

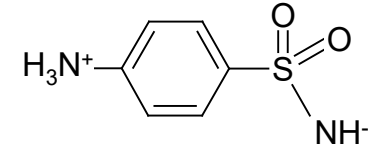

a

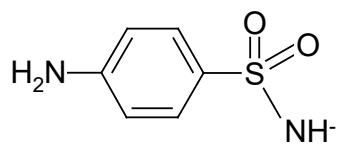

б

Рис. 1. Строение цвиттер-иона (а) и аниона (б) сульфаниламида

Fig. 1. The structure of the zwitter ion (a) and the sulphanilamide anion (b).

Образцы мембран были предоставлены Лабораторией ионики функциональных материалов ИОНХ РАН (зав. лабораторией - д.х.н., проф., член.-корр. РАН Ярославцев А.Б.; мембраны получены и охарактеризованы к.х.н, старшим научным сотрудником ИОНХ РАН Сафроновой Е.Ю.). Они получены методом отливки из раствора полимера, содержащего навески допантов с заданной концентрацией. Методика получения мембран подробно описана в работе [21]. Концентрация оксида кремния в мембранах составила 3 мас.\%, протоноакцепторных групп на его поверхности - 5 и 10 мол.\% от содержания оксида. Допант содержала только $1 / 2$ часть пленки, которая в процессе измерений контактировала с исследуемым раствором. Отсутствие допанта в части мембраны, контактирующей с раствором сравнения, необходимо для обеспечения близости его состава с составом раствора внутри мембраны и нивелирования ПД на их границе.

В ПД-сенсорах использовали образцы мембран в $\mathrm{K}^{+}$-форме. Это снижает влияние продуктов диссоциации воды на величину и стабильность их отклика (по сравнению $\mathrm{c} \mathrm{H}^{+}$-формой), а также обеспечивает полноту процесса «регенерации» мембран после их контакта с полиионными растворами. Раствором сравнения ПДсенсоров был $1 \mathrm{M}$ раствор КСI.

Для «регенерации» мембран после длительного использования (не менее 3 месяцев) их выдерживали в 2 М растворе КСI (72 ч) и промывали бидистиллированной водой. Между сериями повторных ( 100) измерений образцы выдерживали в $0.1 \mathrm{M}$ растворе $\mathrm{KCI}$ (30 мин) при постоянном перемешивании.

Методы исследования. Ячейка для оценки откликов системы ПД-сенсоров состояла из двух корпусов из непроводящего материала. Внутренний корпус ячейки заполняли исследуемым раствором, секции внешнего корпуса - раствором сравнения. Гибридные мембраны погружались в исследуемый раствор концом модифици- 
рованной части, а в раствор сравнения - концом немодифицированной части (на 3-5 мм). Хлоридсеребряный электрод (ЭСр-10103, ООО «Эконикс-эксперт»), подключенный к входу многоканального потенциометра для электрода сравнения, погружали в исследуемый раствор. Хлоридсеребряные электроды (ЭСр-10103, ООО «Сенсорные Системы»), подключенные к измерительным входам, погружали в секции с раствором сравнения. С помощью многоканального аналого-цифрового преобразователя измеряли напряжение нескольких цепей вида:

$\mathrm{Ag}|\mathrm{AgCl}, 1 \mathrm{M} \mathrm{KCl}|$ мембрана $\mid$ исследуемый раствор $\mid$ нас. $\mathrm{KCl}, \mathrm{AgCl} \mid \mathrm{Ag}$.

С помощью стеклянного электрода (ЭС-10301/7, ООО «Эконикс-эксперт») измеряли $\mathrm{pH}$ исследуемого раствора одновременно с измерением откликов ПД-сенсоров.

Воспроизводимость откликов ПД-сенсоров в исследуемом растворе оценивали с помощью дисперсии отклика $\left(\mathrm{s}^{2}, \mathrm{MB}^{2}\right)$, а стабильность откликов - на основе результатов хронопотенциометрических измерений в течение 1 ч и сопоставлением градуировочных характеристик ПД-сенсоров после их использования в течение не-

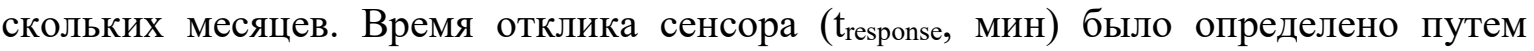
сравнения разброса его значений в течение времени измерения с разбросом при дублировании эксперимента. Дрейф отклика определяли как изменение потенциала в единицу времени (мВ/ч) после его установления.

Для расчета коэффициентов градуировочных уравнений использовали многофакторный регрессионный анализ, учитывая влияние на отклик ПД-сенсоров концентрации катионов $\mathrm{K}^{+}$, цвиттер-ионов и анионов сульфаниламида $\left(\mathrm{SA}^{ \pm}, \mathrm{SA}^{-}\right)$и $\mathrm{pH}$ раствора:

$$
\Delta \varphi_{D}=b_{0}+b_{1} \cdot p K+b_{2} \cdot p H+b_{3} \cdot p S A,
$$

где $\Delta \varphi_{D}-$ значение отклика ПД-сенсора, $\mathrm{MB} ; p K$ - отрицательный десятичный логарифм молярной концентрации ионов $\mathrm{K}^{+} ; p S A$ - отрицательный десятичный логарифм суммарной молярной концентрации ионов $\mathrm{SA}^{ \pm}$и $\mathrm{SA}^{-} ; b_{0}$ - свободный член градуировочного уравнения, мВ; $b_{i}-$ коэффициент чувствительности ПД-сенсора к $i$-тому компоненту матрицы, $\mathrm{MB} / \mathrm{p} c$.

Корреляцию между значениями отрицательного десятичного логарифма молярной концентрации ионов в градуировочных растворах (для оценки обусловленности уравнений), а также между откликами пар ПД-сенсоров (для оценки возможности объединения их в массив) оценивали по г-критерию. Адекватность градуировочных уравнений оценивали по $F$-критерию Фишера (для доказательства правильности их выбора и выявления возможных систематических погрешностей).

Для расчета концентраций аналитов в исследуемых растворах решали систему градуировочных уравнений для выбранной пары ПД-сенсоров, используя в качестве экспериментальных данных значения откликов ПД-сенсоров и $\mathrm{pH}$ в исследуемом растворе. Для оценки правильности и воспроизводимости определения аналитов рассчитывали относительную погрешность $(\delta, \%)$ и относительное стандартное отклонение $\left(s_{\mathrm{r}}, \%\right)$, соответственно.

\section{Обсуждение результатов}

ПД-сенсоры на основе исследуемых мембран имеют низкие значения времени установления $\left(\right.$ tresponse $<1$ мин) и дисперсии $\left(\mathrm{s}^{2}=0.8-6 \mathrm{mB}^{2}\right)$ отклика в водных растворах, содержащих сульфаниламид и гидроксид калия в диапазоне концентраций компонентов от $1.0 \cdot 10^{-4}$ до $1.0 \cdot 10^{-2} \mathrm{M}$ (pH 9.33-10.98). При этом дрейф отклика соизмерим с погрешностью его определения или незначим (табл. 1). 
Таблица 1. Время, дрейф и дисперсия отклика ПД-сенсоров в растворе, содержащем $1.0 \cdot 10^{-3} \mathrm{M}$ сульфаниламида и $1.0 \cdot 10^{-3} \mathrm{M}$ гидроксида калия (pH $\left.10.74 \pm 0.07\right)$

Table 1. Time, drift and dispersion of DP-sensors response in solution, containing $1.0 \cdot 10^{-3}$ $\mathrm{M}$ sulphanilamide and $1.0 \cdot 10^{-3} \mathrm{M}$ potassium hydroxide $(\mathrm{pH} 10.74 \pm 0.07)$

\begin{tabular}{|c|c|c|c|}
\hline Мембрана ПД-сенсора & $\begin{array}{c}\text { Время отклика, } \\
\text { мин }\end{array}$ & $\mathrm{s}^{2}, \mathrm{MB}^{2}$ & $\begin{array}{c}\text { Дрейф } \\
\text { отклика, мB/ч }\end{array}$ \\
\hline МФ-4СК & \multirow{6}{*}{$<1$} & 1.8 & не значим \\
\hline МФ-4СК + 3 мас. $\% \mathrm{SiO}_{2}$ & & 0.8 & не значим \\
\hline МФ-4СК + 3 мас.\% $\mathrm{SiO}_{2}(5$ мол. $\% \mathrm{R} 1)$ & & 4 & $4.8 \pm 1.2$ \\
\hline МФ-4СК + 3 мас.\% $\mathrm{SiO}_{2}(10$ мол.\% R1) & & 2 & $5.4 \pm 0.9$ \\
\hline МФ-4СК + 3 мас.\% $\mathrm{SiO}_{2}(5$ мол.\% $\%$ R2) & & 6 & не значим \\
\hline МФ-4СК + 3 мас.\% $\mathrm{SiO}_{2}(10$ мол.\% R2) & & 2 & не значим \\
\hline
\end{tabular}

Чувствительность ПД-сенсоров к ионам $\mathrm{K}^{+}$в исследуемых растворах является высокой для всех образцов мембран, несколько снижаясь до 47.80-49.98 мВ/pc для мембран, содержащих немодифицированный оксид и оксид с 10 мол.\% R2 (рис. 2). Чувствительность ПД-сенсоров к ионам $\mathrm{SA}^{ \pm}$и $\mathrm{SA}^{-}$существенно ниже, чем к ионам $\mathrm{K}^{+}$, однако является значимой (от $2.09 \pm 0.12$ до $7.22 \pm 0.10 \mathrm{mB} / \mathrm{pc}$ ) (рис. 2). Наименьшие значения чувствительности ПД-сенсоров к ионам $\mathrm{SA}^{ \pm}$и $\mathrm{SA}^{-}$также достигаются для образцов, содержащих $\mathrm{SiO}_{2}$ и $\mathrm{SiO}_{2}(10$ мол.\% R2) (рис. 2).

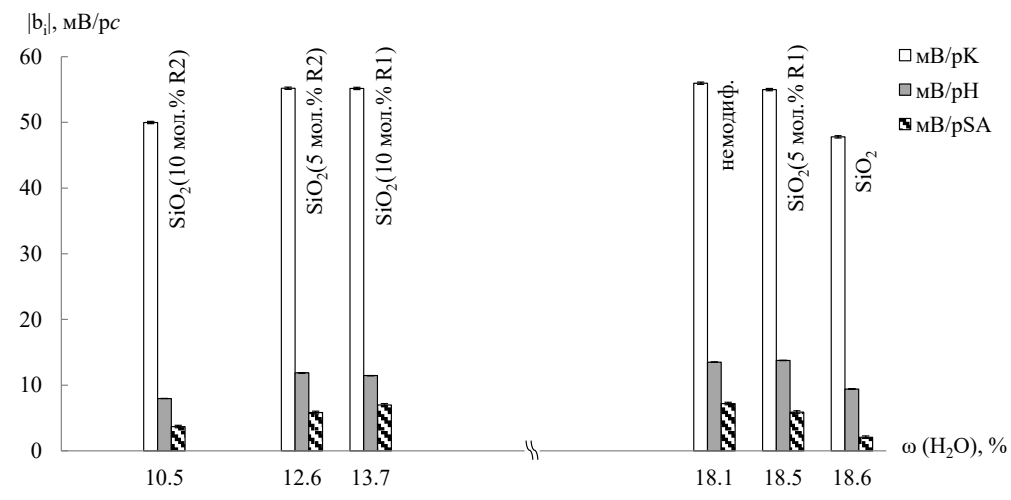

Рис. 2. Зависимость коэффициентов чувствительности ПД-сенсоров к катионам и анионам в щелочных растворах сульфаниламида $\left(c=1.0 \cdot 10^{-4}-1.0 \cdot 10^{-2} \mathrm{M}\right.$, $\mathrm{pH}=9.33-10.98)$ от влагосодержания мембран МФ-4СК +3 мас.\% $\mathrm{SiO}_{2}(\mathrm{R})$

Fig. 2. Dependence of the sensitivity coefficients of DP-sensors to cations and anions in alkaline solutions of sulphanilamide $\left(c=1.0 \cdot 10^{-4}-1.0 \cdot 10^{-2} \mathrm{M}\right.$, $\mathrm{pH}=9.33-10.98$ ) from the water uptake of the MF-4SC +3 wt. $\% \mathrm{SiO}_{2}(\mathrm{R})$ membranes

Вследствие доннановского исключения ионов гидроксила из пор катионообменной мембраны с сильнокислотными группами, $\mathrm{pH}$ раствора внутри мембраны примерно на 2 единицы ниже, чем $\mathrm{pH}$ контактирующего с ней раствора [22]. Учитывая разницу в значениях $\mathrm{pH}$ и константы диссоциации сульфаниламида в мембране, он должен полностью переходить в цвиттер-ионную форму. Наличие в его структуре положительно заряженной ароматической аминогруппы и отрицательно заряженной сульфонамидной группы в радикале может обеспечивать взаимодействие с сульфогруппами мембраны и аминогруппами на поверхности допанта, соответственно. Это, по-видимому, обусловливает значимую чувствительность к аналиту как для ПДсенсора на основе мембраны МФ-4СК, так и на основе модифицированных образцов. Следует отметить, что в ряде предыдущих работ чувствительность ПД-сенсоров к анионам органических амфолитов, способных к протонированию в фазе мембраны, достигала более высоких значений $[18,19]$. Видимо, необменная сорбция ионов 
сульфаниламида затруднена из-за наличия объемных гидрофобных фрагментов в структуре. Это также проявляется в снижении чувствительности ПД-сенсоров к ионам $\mathrm{SA}^{-}, \mathrm{SA}^{ \pm}$при использовании мембраны МФ-4CК + 3 мас.\% $\mathrm{SiO}_{2}$, отличающейся высоким влагосодержанием, но пониженной диффузионной проницаемостью [21], и образца с наиболее объемным допантом (рис. 2). При этом наибольшие значения чувствительности ПД-сенсора к ионам $\mathrm{SA}^{ \pm}$и $\mathrm{SA}^{-}$получены при использовании немодифицированного образца и мембраны МФ-4СК + 3 мас.\% $\mathrm{SiO}_{2}$ (10 мол.\% R1) (рис. 2). В ряду исследуемых мембран данный образец характеризуется более низким влагосодержанием (рис. 2) и наибольшим значением диффузионной проницаемости [21], поэтому концентрация необменно сорбированных частиц аналита для него наибольшая. Симбатное изменение чувствительности к ионам $\mathrm{SA}^{-}, \mathrm{SA}^{ \pm}$и $\mathrm{K}^{+}$, возможно, обусловлено их сопряженным переносом через межфазную границу из-за формирования водородных связей между гидратными оболочками ионов $\mathrm{K}^{+}$и сульфонамидной группы органических ионов.

Для организации мультисенсорной системы была выбрана мембрана МФ-4СК + 3 мас.\% $\mathrm{SiO}_{2}(10$ мол.\% R1) с наиболее высокой чувствительностью к ионам сульфаниламида, а также мембрана МФ-4СК +3 мас.\% $\mathrm{SiO}_{2}$, которые в паре обеспечивают наименьшую корреляцию между откликами сенсоров в системе. Система градуировочных уравнений для определения ионов $\mathrm{SA}^{-}, \mathrm{SA}^{ \pm}$и $\mathrm{K}^{+}$в диапазоне $\mathrm{pH}$ от 9.33 до 10.98 с помощью выбранной пары сенсоров имеет вид:

$$
\left\{\begin{array}{l}
\Delta \varphi_{D}=80.6-47.80 \cdot p K-9.42 \cdot p H+2.09 \cdot p S A ; \\
\Delta \varphi_{D}=107-55.16 \cdot p K-11.46 \cdot p H+7.0 \cdot p S A .
\end{array}\right.
$$

Результаты определения ионов $\mathrm{SA}^{ \pm}, \mathrm{SA}^{-}$и $\mathrm{K}^{+}$в исследуемых растворах представлены в табл. 2. Относительная погрешность и относительное стандартное отклонение определения ионов сульфаниламида составили 3-9 и 8-16\%, соответственно, ионов калия - 0.4-14 и 3-14\%, соответственно.

Таблица 2. Результаты определения ионов $\mathrm{SA}^{ \pm}, \mathrm{SA}^{-}$и $\mathrm{K}^{+}$в водных растворах с помощью мультисенсорной системы на основе мембран МФ-4СК +3 мас.\% $\mathrm{SiO}_{2}$ и МФ-4СК + 3 мас.\% $\mathrm{SiO}_{2}$ (10 мол.\% R1) $(n=5, p=0.95)$

Table 2. Results of the determination of $\mathrm{SA}^{ \pm}, \mathrm{SA}^{-}$and $\mathrm{K}^{+}$ions, in aqueous solutions using a multisensory system based on MF-4SC +3 wt. $\% \mathrm{SiO}_{2}$ and MF-4SC +3 wt. $\% \mathrm{SiO}_{2}$ $(10$ mol.\% R1) membranes $(n=5, p=0.95)$

\begin{tabular}{|c|c|c|c|c|c|c|c|c|}
\hline \multirow{2}{*}{$\begin{array}{c}\mathrm{pH} \pm \\
0.05\end{array}$} & \multicolumn{2}{|c|}{$c_{\text {mеор }}, \mathrm{M}$} & \multicolumn{2}{|c|}{$\bar{c}_{\text {эксn }}, \mathrm{M}$} & \multicolumn{2}{|c|}{$\delta, \%$} & \multicolumn{2}{c|}{$\mathrm{S}_{r}, \%$} \\
\cline { 2 - 9 } & $\mathrm{K}^{+}$ & $\begin{array}{c}\mathrm{SA}^{-} \\
\mathrm{SA}^{ \pm}\end{array}$ & $\mathrm{K}^{+}$ & $\begin{array}{l}\mathrm{SA}^{-}, \\
\mathrm{SA}^{ \pm}\end{array}$ & $\mathrm{K}^{+}$ & $\begin{array}{c}\mathrm{SA}^{-}, \\
\mathrm{SA}^{ \pm}\end{array}$ & $\mathrm{K}^{+}$ & $\begin{array}{c}\mathrm{SA}^{-} \\
\mathrm{SA}^{ \pm}\end{array}$ \\
\hline 9.50 & $1.0 \cdot 10^{-4}$ & $1.0 \cdot 10^{-4}$ & $(1.01 \pm 0.12) \cdot 10^{-4}$ & $(0.94 \pm 0.08) \cdot 10^{-4}$ & 0.6 & 6 & 13 & 10 \\
\hline 10.41 & $5.0 \cdot 10^{-4}$ & $5.0 \cdot 10^{-4}$ & $(4.3 \pm 0.5) \cdot 10^{-4}$ & $(5.4 \pm 0.5) \cdot 10^{-4}$ & 14 & 7 & 14 & 11 \\
\hline 10.28 & $5.0 \cdot 10^{-4}$ & $1.0 \cdot 10^{-3}$ & $(4.36 \pm 0.13) \cdot 10^{-4}$ & $(1.09 \pm 0.12) \cdot 10^{-3}$ & 13 & 9 & 3 & 12 \\
\hline 9.72 & $5.0 \cdot 10^{-4}$ & $5.0 \cdot 10^{-3}$ & $(5.2 \pm 0.4) \cdot 10^{-4}$ & $(4.7 \pm 0.4) \cdot 10^{-3}$ & 3 & 6 & 8 & 10 \\
\hline 10.98 & $1.0 \cdot 10^{-3}$ & $1.0 \cdot 10^{-4}$ & $(1.00 \pm 0.03) \cdot 10^{-3}$ & $(0.91 \pm 0.07) \cdot 10^{-4}$ & 0.4 & 9 & 3 & 8 \\
\hline 10.15 & $1.0 \cdot 10^{-3}$ & $5.0 \cdot 10^{-3}$ & $(0.99 \pm 0.05) \cdot 10^{-3}$ & $(5.2 \pm 0.5) \cdot 10^{-3}$ & 1.4 & 3 & 6 & 10 \\
\hline 9.82 & $1.0 \cdot 10^{-3}$ & $1.0 \cdot 10^{-2}$ & $(0.87 \pm 0.06) \cdot 10^{-3}$ & $(1.08 \pm 0.15) \cdot 10^{-2}$ & 14 & 8 & 8 & 16 \\
\hline
\end{tabular}

Сравнивая характеристики разработанного способа определения ионов сульфаниламида с характеристиками нитритометрии, рекомендованной Государственной Фармакопеей, можно отметить ряд преимуществ. Выполнение анализа с помощью мультисенсорной системы является экспрессным, не требует коррекции рН и использования дополнительных реагентов, а также позволяет выполнять определение 
вспомогательных компонентов в фармацевтических средах и технологических растворах.

\section{Заключение}

Показана возможность использования перфтормембран МФ-4СК, содержащих наночастицы оксида кремния, поверхностно модифицированных протоноакцепторными группами 3-аминопропила и 3-(2-имидазолин-1-ил)пропила, в качестве материала перекрестно чувствительных ПД-сенсоров для совместного определения анионов, цвиттер-ионов сульфаниламида и катионов калия в водных растворах в диапазоне концентраций от $10 \cdot 10^{-4}$ до $1 \cdot 10^{-2} \mathrm{M}$ и $\mathrm{pH}$ от 9.33 до 10.98 . Выявлено влияние влагосодержания, объемной доли допанта и проницаемости для анионов мембран на перекрестную чувствительность ПД-сенсоров к аналитам, поступающим в мембрану в результате ионного обмена и необменной сорбции. Разработанная мультисенсорная система на основе образцов МФ-4СК+3 мас.\% $\mathrm{SiO}_{2}$ и МФ-4СК+3 мас.\% $\mathrm{SiO}_{2}(10$ мол.\% R1) характеризуется относительной погрешностью и относительным стандартным отклонением определения ионов сульфаниламида 3-9 и 8-16\%, соответственно, катионов калия - 0.4-14 и 3-14\%, соответственно. Преимуществами разработанной мультисенсорной системы для определения сульфаниламида в водных растворах по сравнению с рекомендованной Государственной Фармакопеей методикой нитритометрии являются экспрессность, отсутствие необходимости коррекции $\mathrm{pH}$ и использования других реактивов, а также возможность определения сульфаниламида совместно с ионами щелочных металлов, являющимися компонентами фармацевтических и технологических сред.

Исследование выполнено при финансовой поддержке РФФИ и Правительства Воронежской области в рамках научного проекта № 19-48-363008. The reported study was funded by RFBR and Voronezh region Government according to the research project № 19-48-363008.

\section{Список литературы}

1. Dmitrienko S.G., Kochuk E.V., Tolmacheva V.V., Apyari V.V. et al. // Food chemistry. 2015. Vol. 188. pp. 51-56. DOI: 10.1016/j.foodchem.2015.04.123.

2. He B., Chen W. // Journal of the Brazilian Chemical Society. 2016. Vol. 27. N. 12. pp. 2216-2225. DOI: $10.5935 / 0103-5053$. 20160114.

3. Peixoto P.S., Tóth I.V., Segundo M.A., Lima J.L.F.C. // International Journal of Environmental Analytical Chemistry. 2016. Vol. 96. No 2. pp. 185-202. DOI: 10.1080/03067319. 2015.1128539.

4. ГОСТ Р 54904-2012. Продукты пищевые, продовольственное сырье. Метод определения остаточного содержания сульфаниламидов, нитроимидазолов, пенициллинов, амфениколов с помощью высокоэффективной жидкостной хроматографии с массспектрометрическим детектором. М. Стандартинформ. 2013. 23 с.
5. ФС.2.1.0038.15 Сульфаниламид. Режим доступа: http://pharmacopoeia.ru/fs-2-10038-15-sulfanilamid/ (дата обращения: 14.10.2020).

6. Maggira M., Deliyanni E.A., Samanidou V.F. // Molecules. 2019. Vol. 24. No 11. P. 2086. DOI: 10.3390/molecules24112086.

7. Амелин В.Г., Волкова Н.М., Тимофеев А.А., Третьяков А.В. // Журнал аналитической химии. 2015. Т. 70. № 9. С. 948-956. DOI: $10.7868 / \mathrm{S} 0044450215090029$.

8. Li Z., Li Y., Qi M., Zhong S. et al. // Journal of Separation Science. 2016. Vol. 39. No 19. pp. 3818-3826. DOI: 10.1002/ jssc. 201600308 .

9. Ji H., Wu Y., Duan Z., Yang F., Yuan H. et al. // Electrophoresis. 2017. Vol. 38. No 3-4. pp. 452-459. DOI: 10.1002/elps.201600364.

10. Errayess S.A., Lahcen A.A., Idrissi L., Marcoaldi C. et al. // Spectrochimica Acta Part A: Molecular and Biomolecular Spectroscopy. 
2017. Vol. 181. pp. 276-285. DOI: 10.1016/j.saa.2017.03.061.

11. Zamora-Gálvez A., Ait-Lahcen A., Mercante L.A., Morales-Narváez E. et al. // Analytical chemistry. 2016. Vol. 88. No 7. pp. 35783584. DOI: 10.1021/acs.analchem.5b04092.

12. He B., Yan S. // International Journal of Electrochemical Science. 2017. Vol. 12. pp. 3001-3011. DOI: 10.20964/2017.04.56.

13. Yadav S.K., Choubey P.K., Agrawal B., Goyal R.N. // Talanta. 2014. Vol. 118. pp. 96103. DOI: $10.1016 / j$.talanta.2013.09.061.

14. Kamel A.H., Almeida S.A., Sales M.G.F., Moreira F.T. // Analytical Sciences. 2009. Vol. 25. No 3. pp. 365. DOI: 10.2116/analsci.25.365.

15. Soleymanpour A., Rezvani S.A. // Materials Science and Engineering: C. 2016. Vol. 58. p. 504. DOI: 10.1016/j.msec.2015.08.034.

16. Харитонов С.В., Горелов И.П. // Химико-фармачевтический журнал. 2000. Т. 34. № 12. C. 45.

17. Bourais I., Maliki S., Mohammadi H., Amine A. // Enzyme and Microbial Technology.
2017. Vol. 96. pp. 23-29. DOI: 10.1016/j.enzmictec.2016.09.007.

18. Safronova E., Parshina A., Kolganova T., Bobreshova O. et al. // Journal of Electroanalitical Chemistry. 2018. Vol. 816. pp. 21-29. DOI: 10.1016/J.JELECHEM.2018.03.028.

19. Паршина А.В., Титова Т.С., Евдокимова Д.Д., Бобрешова О.В. и др. // Мембраны и мембранные технологии. 2019. Т. 9. № 4. С. 256-265. DOI: 10.1134/S2218117219040072.

20. Chienthavorn O., Smith R.M. // Chromatographia. 1999. Vol. 50. No 7-8. pp. 485-489. DOI: 10.1007/BF02490746.

21. Михеев А.Г., Сафронова Е.Ю., Ярославцев А.Б. // Мембраны и мембранные технологии. 2013. Т. 3. № 2. С. 93-99. DOI: $10.1134 / \mathrm{S} 2218117213020090$.

22. Сарапулова В.В., Клевцова А.В., Письменская Н.Д. // Мембраны и мембранные технологии. 2020. Т. 10. № 4. С. 281-292. DOI: $10.1134 / \mathrm{S} 2218117220040100$.

\title{
A potentiometric multisensory system based on MF-4SC membranes containing silica with a functionalized surface for the determination of sulphanilamide and potassium ions
}

\author{
(C) 2020 Yelnikova A.S., Kolganova T.S., Parshina A.V., Bobreshova O.V. \\ Voronezh State University, Voronezh, Russian Federation
}

\begin{abstract}
Sulphanilamide preparations are widely used in medicine and veterinary medicine. HPLC, capillary electrophoresis, spectrophotometry, and titrimetry are used for the control of the content of residual amounts of sulphanilamides in food, drinking water, environmental objects, and the analysis of pharmaceuticals. In the same time, the number of sensors for their determination is limited. The aim of the study was the development of potentiometric multisensory system with DP-sensors (DP - Donnan potential) for the determination of anions and zwitter ions of sulphanilamide together with potassium cations in aqueous solutions in a wide $\mathrm{pH}$ range. The materials of DP-sensors were perfluoromembranes MF-4SC, containing silica nanoparticles with a surface modified with 3-aminopropyl and 3-(2-imidazolin-1-yl) propyl groups. The sensitivity of DP-sensors based on the studied membranes to zwitter ions and sulphanilamide anions was significant in the concentration range from $1.0 \cdot 10^{-4}$ to $1.0 \cdot 10^{-2} \mathrm{M}$. This was due to the protonation of sulphanilamide anions in the membrane caused by the difference in $\mathrm{pH}$ of the external and internal solutions. In this case, the presence in the structure of the analyte of a positively charged aromatic amino group and a negatively charged sulphanilamide group ensured the interaction with membrane sulphogroups and amino groups on the dopant surface, respectively. For the organization of the multisensory system, the MF-4SC $+3 \mathrm{wt} . \% \mathrm{SiO}_{2}(10 \mathrm{~mol} . \% \mathrm{R} 1)$ membrane with the highest sensitivity to sulphonamide ions and MF-4SC $+3 \mathrm{wt} . \% \mathrm{SiO}_{2}$ membrane were chosen. These membranes paired up provide the smallest correlation between the responses of sensors in the system. The relative error and relative standard deviation of the determination of sulphanilamide ions were 3-9 and 8-16\%, potassium ions - $0.4-14$ and 3-14\%, respectively. Benefits of the developed multisensory system for the determination of sulphanilamide in aqueous solutions in comparison with nitrite titration methodology recommended by the State Pharmacopoeia are rapidity, no need for $\mathrm{pH}$ correction and the use of other reagents, as well as the possibility of simultaneous determination of sulphanilamide with alkali metal ions, which are components of pharmaceutical and technological media.
\end{abstract}

Keywords: DP-sensors, multisensory systems, perfluorosulphonic acid membranes, silica, functionalisation of the dopant surface, hybrid materials, sulphanilamide. 


\section{References}

1. Dmitrienko S.G., Kochuk E.V., Tolmacheva V.V., Apyari V.V. et al., Food chemistry, 2015, Vol. 188, pp. 51-56. DOI: 10.1016/j.foodchem.2015.04.123.

2. He B., Chen W., J. Braz. Chem. Soc., 2016, Vol. 27, No 12, pp. 2216-2225. DOI: 10.5935/0103-5053.20160114.

3. Peixoto P.S., Tóth I.V., Segundo M.A., Lima J.L.F.C., Int. J. Environ. Anal. Chem., 2016, Vol. 96, No 2, pp. 185-202. DOI: 10.1080/03067319.2015.1128539.

4. GOST R 54904-2012. Food products, food raw materials. Method for determination of sulfonamides, nitroimidazoles, penicillins, amphenicols by high performance liquid chromatography - mass spectrometry, M., Standartinform, 2013, $23 \mathrm{p}$.

5. FS.2.1.0038.15 Sulfanilamid. Available at: $\quad \mathrm{http}: / /$ pharmacopoeia.ru/fs-2-1-0038-15sulfanilamid/ (accessed 14 October 2020).

6. Maggira M., Deliyanni E.A., Samanidou V.F., Molecules, 2019, Vol. 24, No 11, P. 2086. DOI: 10.3390/molecules24112086.

7. Amelin V.G., Volkova N.M., Timofeev A.A., Tretyakov A.V., J. of Anal. Chem., 2015, Vol. 70 , No 9, pp. 1076-1084. DOI: $10.7868 / \mathrm{S} 0044450215090029$.

8. Li Z., Li Y., Qi M., Zhong S. et al., J. Sep. Sci., 2016, Vol. 39, No 19, pp. 38183826. DOI: $10.1002 /$ jssc. 201600308 .

9. Ji H., Wu Y., Duan Z., Yang F. et al., Electrophoresis, 2017, Vol. 38, No 3-4, pp. 452-459. DOI: 10.1002/elps.201600364.

10. Errayess S.A., Lahcen A.A., Idrissi L., Marcoaldi C et al., Spectrochim. Acta A Mol. Biomol. Spectrosc, 2017, Vol. 181, pp. 276-285. DOI: 10.1016/j.saa.2017.03.061.

11. Zamora-Gálvez A., Ait-Lahcen A., Mercante L.A., Morales-Narváez E. et al., Anal.

Ельникова Анастасия Сергеевна - магистрант 2 г.о., кафедра аналитической химии, Воронежский государственный университет, Воронеж

Колганова Татьяна Сергеевна - к.х.н., преподаватель, кафедра аналитической химии, Воронежский государственный университет, Воронеж

Паршина Анна Валерьевна - д.Х.н., доцент, кафедра аналитической химии, Воронежский государственный университет, Воронеж

Бобрешова Ольга Владимировна - д.х.н., професcop, главный научный сотрудник, кафедра аналитической химии, Воронежский государственный университет, Воронеж
Chem., 2016, Vol. 88, No 7, pp. 3578-3584. DOI: 10.1021/acs.analchem.5b04092.

12. He B., Yan S., Int. J. Electrochem. Sci., 2017, Vol. 12, pp. 3001-3011. DOI: 10.20964/2017.04.56.

13. Yadav S.K., Choubey P.K., Agrawal B., Goyal R.N., Talanta, 2014, Vol. 118, pp. 96103. DOI: 10.1016/j.talanta.2013.09.061.

14. Kamel A.H., Almeida S.A., Sales M.G.F., Moreira F.T., Anal Sci., 2009, Vol. 25, No 3, pp. 365. DOI: 10.2116/analsci.25.365.

15. Soleymanpour A., Rezvani S.A., Mater. Sci. Eng. C, 2016, Vol. 58, pp. 504. DOI: 10.1016/j.msec.2015.08.034.

16. Kharitonov S.V., Gorelov I.P., Pharm. Chem. J., 2000, Vol. 34, No 12, pp. 673.

17. Bourais I., Maliki S., Mohammadi H., Amine A., Enzyme Microb. Technol., 2017, Vol. 96, pp. 23-29. DOI: 10.1016/j.enzmictec.2016.09.007.

18. Safronova E., Parshina A., Kolganova T., Bobreshova O. et al., J. Electroanal. Chem., 2018, Vol. 816, pp. 21-29. DOI: 10.1016/J.JELECHEM.2018.03.028.

19. Parshina A.V., Titova T.S., Evdokimova D.D., Bobreshova O.V. et al., Membranes and Membrane Technologies, 2019, Vol. 1, No 4, pp. 220-228. DOI: 10.1134/S2517751619040073.

20. Chienthavorn O., Smith R.M., Chromatographia, 1999, Vol. 50, No 7-8, pp. 485-489. DOI: $10.1007 / \mathrm{BF} 02490746$.

21. Mikheev A.G., Safronova E.Y., Yaroslavtsev A.B., Pet. Chem., 2013, Vol. 53, No 7, pp. 504-510. DOI: 10.1134/ S0965544113070104.

22. Sarapulova V.V., Klevtsova A.V., Pismenskaya N.D., Membranes and Membrane Technologies, 2020, Vol. 2, No 4, pp. 272-282. DOI: $10.1134 / \mathrm{S} 2517751620040101$.

Yelnikova Anastasia S. - 2-nd year master's student, Department of Analytical Chemistry, Voronezh State University, Voronezh

Kolganova Tatyana S. - PhD in Chemistry, lecturer, Department of Analytical Chemistry, Voronezh State University, Voronezh

Parshina Anna V. - Doctor of Chemical Sciences, Associate Professor, Department of Analytical Chemistry, Voronezh State University, Voronezh parshina ann@mail.ru

Bobreshova Olga V. - Doctor of Chemical Sciences, professor, chief researcher, Department of Analytical Chemistry, Voronezh State University, Voronezh 